\title{
Kinetic Study of Esterification of Sulfuric Acid with Alcohols in Aerosol Bulk Phase
}

Jiaying Li and Myoseon Jang*

Department of Environmental Engineering Sciences P.O. Box 116450, University of Florida, Gainesville, Florida 32611

Correspondence to: M. Jang (email: mjang@ufl.edu)

\section{Supplementary Materials}

Number of Sections: 4

Number of Figures: 4 


\section{Section 1: Description of indoor chamber experiment}

All chamber experiments shown in table 3 were conducted in a $2-\mathrm{m}^{3}$ indoor Teflon film chamber described previously (Czoschke and Jang 2006). The chamber was flushed with air purified by a clean air generator (Aadco Model 737) before each experiment. The particle number concentration and population were measured using a scanning mobility particle sizer (TSI, SMPS Model 3080) associated with a condensation nuclei counter (TSI, Model 3025A). The humidity of the chamber air was controlled by passing the clean dry air through a water bubbler. The temperatures for chamber experiments were 295 to $298 \mathrm{~K}$.

\section{Section 2: Organosulfate formation from the reaction between glyoxal or glycerol with $\mathrm{D}_{2} \mathrm{SO}_{4}{ }^{-}$ $\mathrm{D}_{2} \mathrm{O}$ solution}

To identify organosulfate products, glyoxal or glycerol was mixed with excess amounts of the $\mathrm{D}_{2} \mathrm{SO}_{4}-\mathrm{D}_{2} \mathrm{O}$ solution and monitored using ${ }^{1} \mathrm{H}-\mathrm{NMR}$. The fraction of $\mathrm{D}_{2} \mathrm{SO}_{4}$ in the solution is $50 \mathrm{wt} \%$ which is equivalent to $\mathrm{RH}$ of $35.5 \%$ at $298 \mathrm{~K}$. Compared to the ${ }^{1} \mathrm{H}-\mathrm{NMR}$ spectrum of the glyoxal in $\mathrm{D}_{2} \mathrm{O}$, the ${ }^{1} \mathrm{H}$-NMR spectrum of the glyoxal- $\mathrm{D}_{2} \mathrm{SO}_{4}$ solution shows the formation of organosulfate appearing at $6.13 \mathrm{ppm}$ (Figure S1B). The peak intensity at $6.13 \mathrm{ppm}$ kept increasing over 36 hours after glyoxal was mixed with the $\mathrm{D}_{2} \mathrm{SO}_{4}-\mathrm{D}_{2} \mathrm{O}$ solution, indicating that the formation of organosulfate products progresses slowly in the solution. Figure S1D shows the ${ }^{1} \mathrm{H}-\mathrm{NMR}$ spectrum of glycerol in the $\mathrm{D}_{2} \mathrm{SO}_{4}-\mathrm{D}_{2} \mathrm{O}$ solution three days after mixing. Peaks d-g in Figure S1D which appeared 2 hours after glycerol is mixed with $\mathrm{D}_{2} \mathrm{SO}_{4}-\mathrm{D}_{2} \mathrm{O}$ indicate organosulfates formation though the reaction of glycerol and sulfuric acid in the highly concentrated sulfuric acid solution. The structures of oranosulfate products were proposed based on the chemical shifts of those compounds in the NMR spectra and shown in Figure S1. 


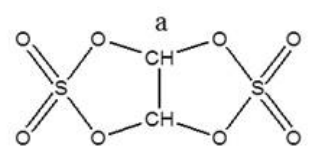

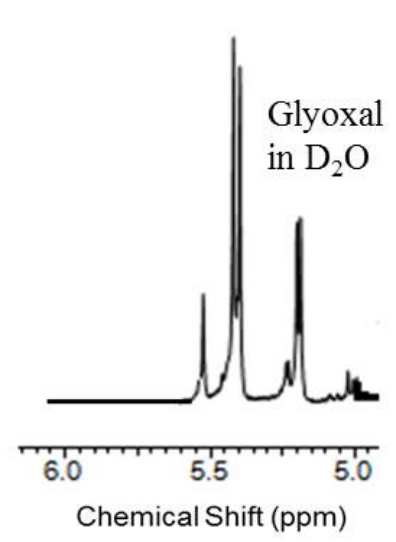

A

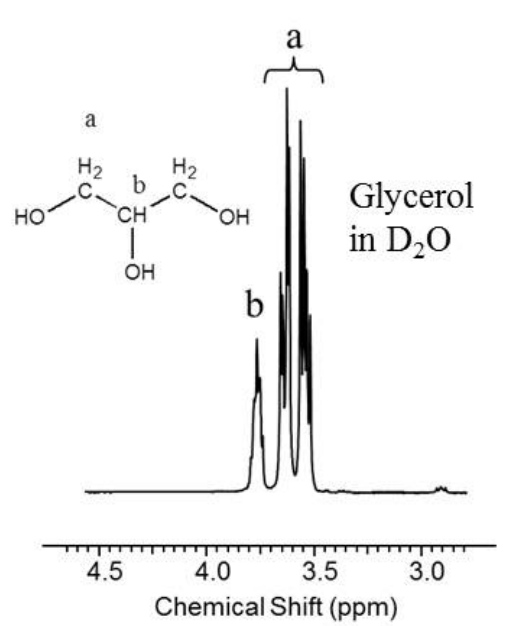

C

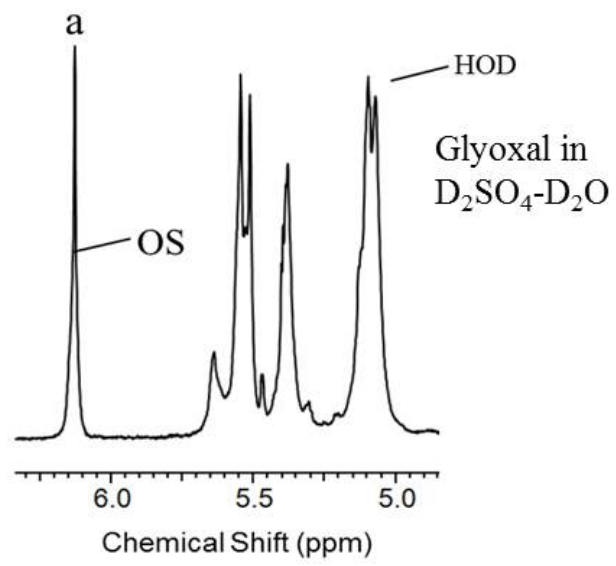

B

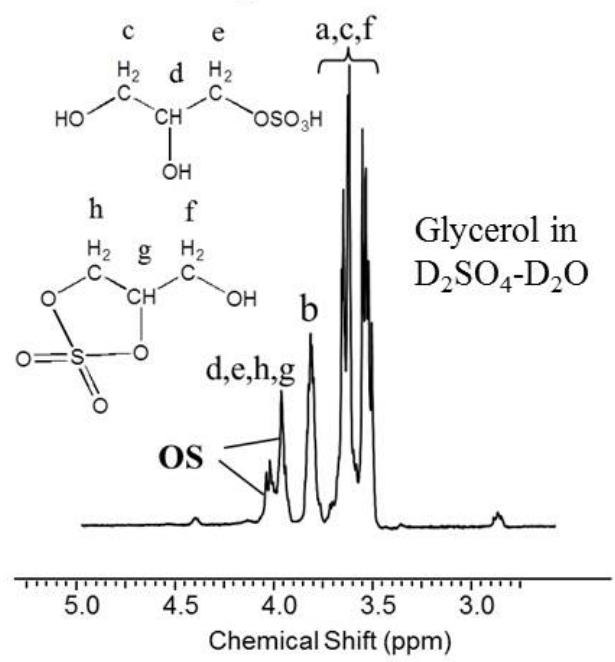

D

Figure $\mathrm{S} 1$. NMR spectra of glyoxal in $\mathrm{D}_{2} \mathrm{O}$, glyoxal in $\mathrm{D}_{2} \mathrm{SO}_{4}-\mathrm{D}_{2} \mathrm{O}$ solution, glycerol in $\mathrm{D}_{2} \mathrm{O}$, and glycerol in $\mathrm{D}_{2} \mathrm{SO}_{4}-\mathrm{D}_{2} \mathrm{O}$ solution (glyoxal: $\mathrm{D}_{2} \mathrm{SO}_{4}=1: 5.67$ and glycerol: $\mathrm{D}_{2} \mathrm{SO}_{4}=1: 8.92$ in mole ratio). The $\mathrm{D}_{2} \mathrm{SO}_{4}{ }^{-}$ $\mathrm{D}_{2} \mathrm{O}$ solution solution was made by 1:1 mass ratio, which is equivalent to the $\mathrm{D}_{2} \mathrm{SO}_{4}$ aerosol composition at relative humidity $=35.5 \%$ at $298 \mathrm{~K}$.

Section 3: Measurements of aerosol water content using FTIR 


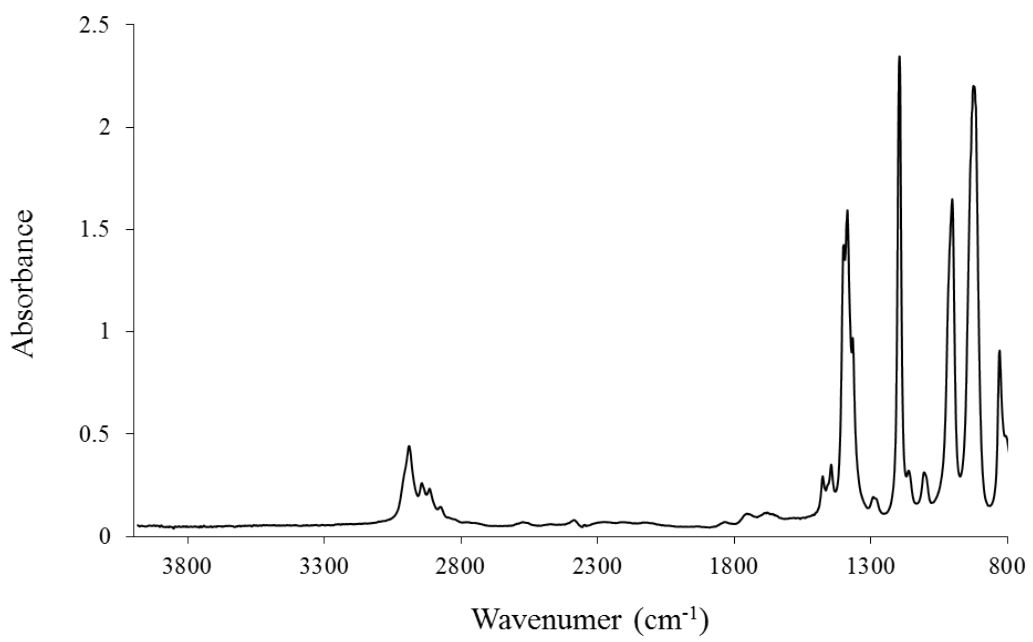

Figure S2. The FTIR spectrum of diethyl sulfate at $\mathrm{RH}=60 \%$ under room temperature. 

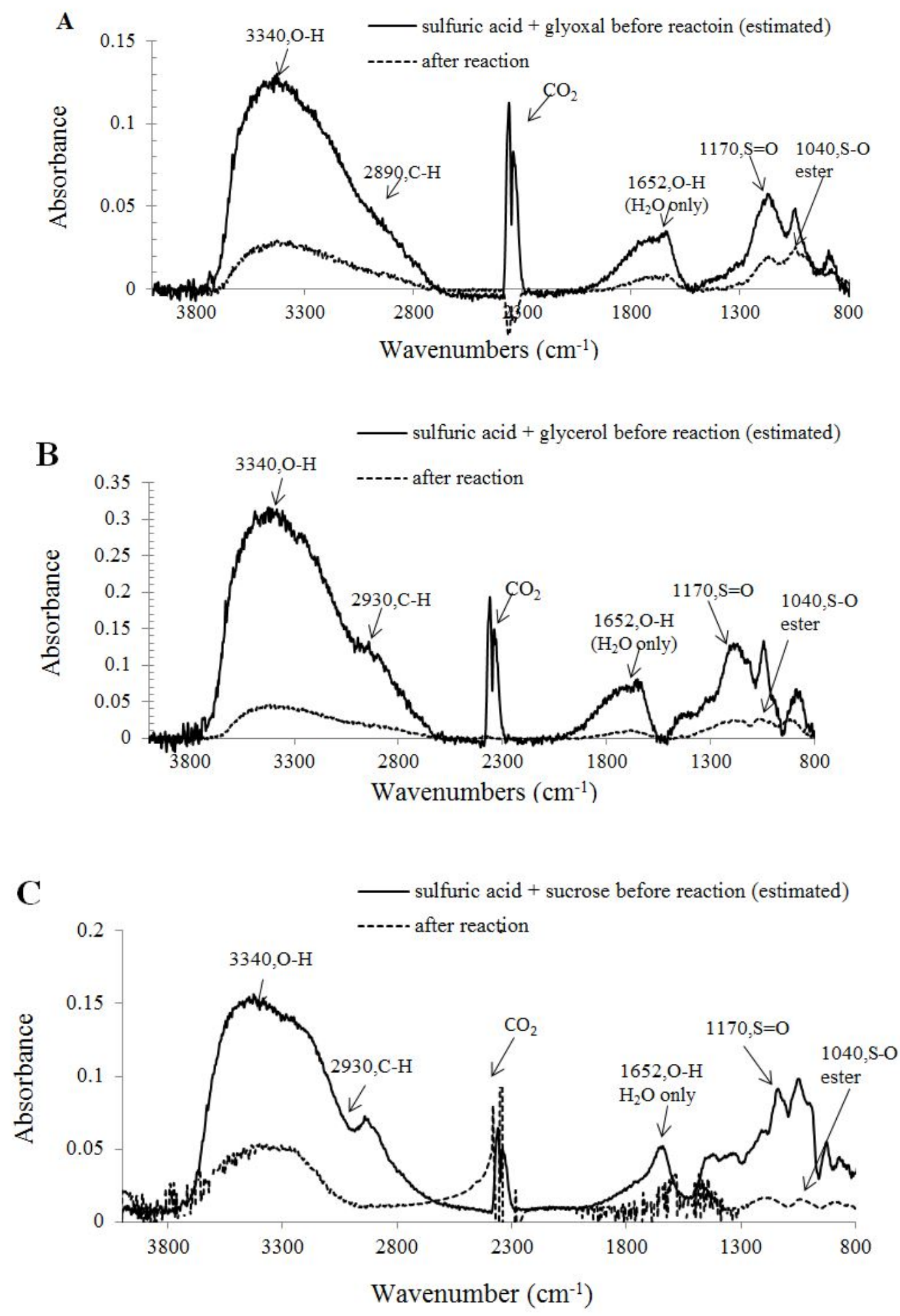

FIGURE S3. FTIR spectra as a sum of the contribution from $\mathrm{H}_{2} \mathrm{SO}_{4}$ and glyoxal aerosol (A), $\mathrm{H}_{2} \mathrm{SO}_{4}$ and glycerol aerosol (B), and $\mathrm{H}_{2} \mathrm{SO}_{4}$ and sucrose aerosol (C), assuming no reaction in aerosol (before reaction), and FTIR spectra of the internally mixed multialcohol- $\mathrm{H}_{2} \mathrm{SO}_{4}$ aerosol (after reaction). The experimental conditions for FTIR studies are listed in Table 2. 


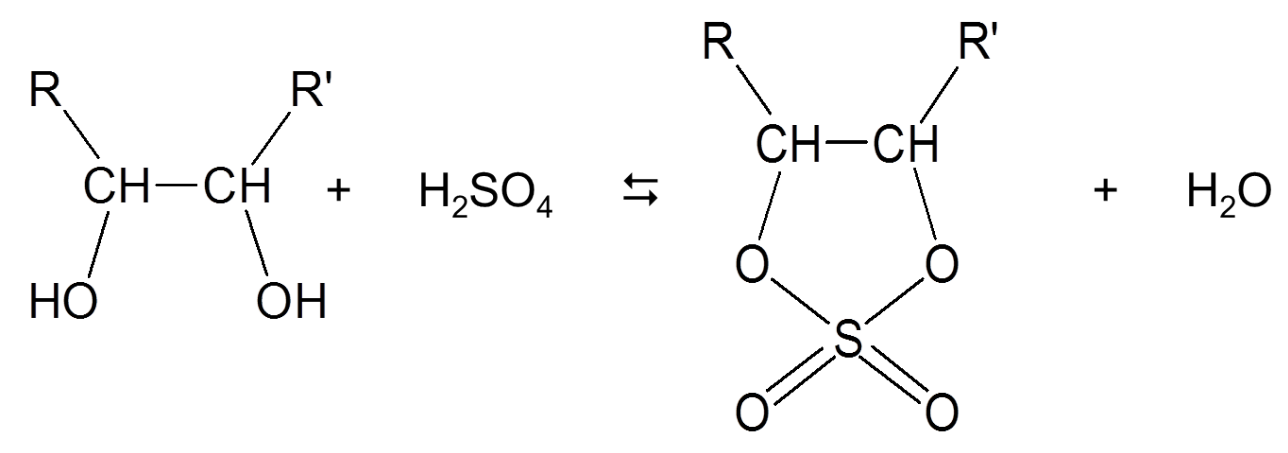

$(\mathrm{MOH})$

(cy-diOS)

Figure S4. Formation of cyclic dialkylsulfate (cy-diOS) in the multialcohol-sulfuric acid aerosol.

\section{Section 4: Derivation of Equation 13 in manuscript}

\section{Nomenclature}

$\mathrm{k}_{2}$ : forward and backward reaction rate constant for multiacohol- $\mathrm{H}_{2} \mathrm{SO}_{4}$ reaction $\left(\mathrm{L} \mathrm{mol}{ }^{-1} \mathrm{~min}^{-1}\right.$ )

$\mathrm{k}_{-2}$ : backward reaction rate constant for multiacohol- $\mathrm{H}_{2} \mathrm{SO}_{4}$ reaction $\left(\mathrm{L} \mathrm{mol}^{-1} \mathrm{~min}^{-1}\right)$

[cy-diOS]: concentration of cyclic dialkylsulfate in aerosol $\left(\mathrm{mol} \mathrm{L}^{-1}\right)$

$\left[\mathrm{H}_{2} \mathrm{O}\right]$ : water concentration in aerosol $\left(\mathrm{mol} \mathrm{L}^{-1}\right)$

$\left[\mathrm{H}_{2} \mathrm{SO}_{4}\right]_{0}$ : initial concentration of sulfuric acid in aerosol $\left(\mathrm{mol} \mathrm{L}^{-1}\right)$

$\left[\mathrm{H}_{2} \mathrm{SO}_{4}\right]_{t}$ : concentration of sulfuric acid in aerosol at reaction time $t\left(\mathrm{~mol} \mathrm{~L}^{-1}\right)$

$\mathrm{M}_{M O H, 0}$ : initial total mass concentration of a multiacohol in the chamber $\left(\mathrm{g} \mathrm{m}^{-3}\right)$

$\mathrm{M}_{M O H, t}$ : total mass concentration of a multiacohol in the chamber at reaction time $t\left(\mathrm{~g} \mathrm{~m}^{-3}\right)$

$[\mathrm{MOH}]_{t}$ : concentration of a multiacohol in aerosol at reaction time $t\left(\mathrm{~mol} \mathrm{~L}^{-1}\right)$

$\mathrm{MW}_{M O H}$ : molecular weight of a multiacohol $\left(\mathrm{g} \mathrm{mol}^{-1}\right)$

$\mathrm{K}_{\text {in }}$ : partitioning coefficient of an organic compound onto inorganic particles $\left(\mathrm{m}^{3} \mu \mathrm{g}^{-1}\right)$

$\mathrm{M}_{i n}$ : mass concentration of inorganic aerosol in the chamber $\left(\mu \mathrm{g} \mathrm{m} \mathrm{m}^{-3}\right)$

$\mathrm{V}_{\text {conc }}$ : volume concentration of the aerosol in the chamber $\left(\mathrm{L} \mathrm{m}^{-3}\right)$

\section{Derivation of analytical solution}

The cyclic dialkylsulfate (cy-diOS) formation in multiacohol- $\mathrm{H}_{2} \mathrm{SO}_{4}$ aerosol can be expressed as Figure S4 (Fig. 6 in manuscript). $\mathrm{MOH}$ is a multialcohol, and both $\mathrm{R}$ and $\mathrm{R}$ are $\mathrm{H}$, alkyls or $\mathrm{OH}$ groups. Similar to 1-heptanol, $\mathrm{MOH}$ is distributed between both gas phase and aerosol phase depending on the volatility. The aerosol phase concentration $\left([\mathrm{MOH}]_{t}\right)$ of a multiacohol $(\mathrm{MOH})$ at reaction time $t$ was estimated using the partitioning coefficient of a $\mathrm{MOH}$ onto inorganic particles $\left(\mathrm{K}_{i n}\right)$, the mass concentration of inorganic aerosol in the chamber $\left(\mathrm{M}_{i n}\right)$, the total mass concentration of the $\mathrm{MOH}\left(\mathrm{M}_{M O H, t}\right)$ in the chamber at reaction time $t$, and the aerosol volume concentration $\left(\mathrm{V}_{\text {conc }}\right)$.

$$
[M O H]_{t}=\frac{K_{i n} M_{i n}}{\left(1+K_{i n} M_{i n}\right) V_{c o n c} M W_{M O H}} M_{M O H, t}
$$


$\mathrm{M}_{M O H, t}$ can be estimated using the difference between initial total mass concentration of a multiacohol in the chamber $\left(\mathrm{M}_{\mathrm{MOH}, 0}\right)$, and the consumed $\mathrm{MOH}$ during the reaction. Since the consumption of MOH equals that of sulfuric acid, and term $\frac{K_{i} n M_{i} n}{1+K_{i} n M_{i} n}$ is defined as $\alpha$, then,

$$
M_{M O H, t}=M_{M O H, 0}-\left(\left[\mathrm{H}_{2} \mathrm{SO}_{4}\right]_{0}-\left[\mathrm{H}_{2} \mathrm{SO}_{4}\right]_{t}\right) V_{\text {conc }} M W_{M O H}
$$

As shown in Figuire S4, the consumption of sulfuric acid is governed by both forward reaction rate constant $\left(\mathrm{k}_{2}\right)$ and backward reaction rate constant $\left(\mathrm{k}_{-2}\right)$. The consumption rate is described as below:

$$
\frac{d\left[\mathrm{H}_{2} \mathrm{SO}_{4}\right]}{d t}=-k_{2}[\mathrm{MOH}]_{t}\left[\mathrm{H}_{2} \mathrm{SO}_{4}\right]_{t}+k_{-2}[c y-d i O S]\left[\mathrm{H}_{2} \mathrm{O}\right]
$$

Since

$$
[c y-d i O S]=\left[\mathrm{H}_{2} \mathrm{SO}_{4}\right]_{0}-\left[\mathrm{H}_{2} \mathrm{SO}_{4}\right]_{t}
$$

Combine Eqs. (S1) - (S4),

(5)

$\frac{d\left[\mathrm{H}_{2} \mathrm{SO}_{4}\right]}{d t}=-k_{2} \frac{\alpha\left\{\mathrm{M}_{\mathrm{MOH}, 0}-\left(\left[\mathrm{H}_{2} \mathrm{SO}_{4}\right]_{0}-\left[\mathrm{H}_{2} \mathrm{SO}_{4}\right]_{t}\right) V_{\mathrm{conc}} \mathrm{MW} W_{M O H}\right\}}{V_{\text {conc }} M W_{M O H}}\left[\mathrm{H}_{2} \mathrm{SO}_{4}\right]_{t}+k_{-2}\left(\left[\mathrm{H}_{2} \mathrm{SO}_{4}\right]_{0}-\left[\mathrm{H}_{2} \mathrm{SO}_{4}\right]_{t}\right)\left[\mathrm{H}_{2} \mathrm{O}\right]$

Term

$$
\sqrt{\left(\frac{k_{2} \alpha M_{M O H, 0}}{V_{\text {conc }} M W_{M O H}}-k_{2} \alpha\left[H_{2} S_{4}\right]_{0}+k_{-2}\left[H_{2} O\right]\right)^{2}+4 k_{2} k_{-2} \alpha\left[H_{2} S O_{4}\right]_{0}\left[H_{2} O\right]}
$$

is defined as $\beta$, then, Eq. (S5) was reformed into

(7)

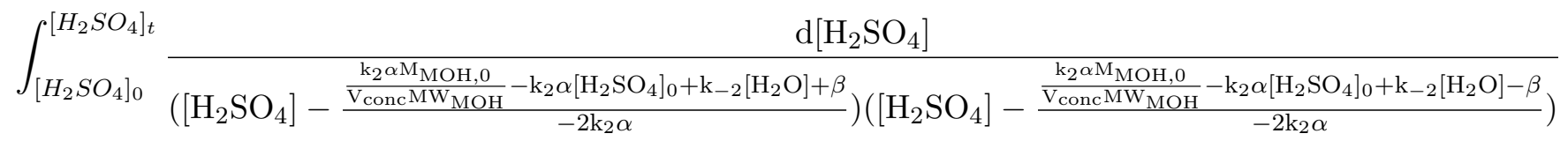

$$
\begin{aligned}
& =\int_{0}^{t}-\mathrm{k}_{2} \alpha \mathrm{d} t
\end{aligned}
$$

After integration, 
(8)

$$
\begin{gathered}
\ln \left\{\frac{2 k_{2} \alpha\left[H_{2} S O_{4}\right]_{t}+\frac{k_{2} \alpha M_{M O H, 0}}{V_{c o n c} M W_{M O H}}-k_{2} \alpha\left[H_{2} S O_{4}\right]_{0}+k_{-2}\left[H_{2} O\right]+\beta}{2 k_{2} \alpha\left[H_{2} S O_{4}\right]_{t}+\frac{k_{2} \alpha M_{M O H, 0}}{V_{c o n c} M W_{M O H}}-k_{2} \alpha\left[H_{2} S O_{4}\right]_{0}+k_{-2}\left[H_{2} O\right]-\beta}\right\}-\ln \left\{\frac{\frac{k_{2} \alpha M_{M O H, 0}}{V_{c o n c} M W_{M O H}}+k_{2} \alpha\left[H_{2} S O_{4}\right]_{0}+k_{-2}\left[H_{2} O\right]+\beta}{\frac{k_{2} \alpha M_{M O H, 0}}{V_{c o n c} M W_{M O H}}+k_{2} \alpha\left[H_{2} S O_{4}\right]_{0}+k_{-2}\left[H_{2} O\right]-\beta}\right\} \\
=-\beta t
\end{gathered}
$$

Term

$$
\exp \left\{\ln \left(\frac{\frac{k_{2} \alpha M_{M O H, 0}}{V_{\text {conc } M W_{M O H}}}+k_{2} \alpha\left[H_{2} S O_{4}\right]_{0}+k_{-2}\left[H_{2} O\right]+\beta}{\frac{k_{2} \alpha M_{M O H, 0}}{V_{c o n c} M W_{M O H}}+k_{2} \alpha\left[H_{2} S O_{4}\right]_{0}+k_{-2}\left[H_{2} O\right]-\beta}\right)+\beta t\right\}
$$

is defined as $\epsilon$, thus,

$$
\left[\mathrm{H}_{2} \mathrm{SO}_{4}\right]_{t}=-\frac{M_{M O H, 0}}{2 V_{\text {conc }} M W_{M O H}}+\frac{\left[H_{2} S O_{4}\right]_{0}}{2}-\frac{k_{-2}\left[H_{2} O\right]}{2 k_{2} \alpha}+\frac{\beta(1+\epsilon)}{2 k_{2} \alpha(\epsilon-1)}
$$




\section{References}

Czoschke, N. and Jang, M. (2006). Acidity effects on the formation of alpha-pinene ozone SOA in the presence of inorganic seed. Atmospheric Environment 40:4370-4380. 